\title{
The Role of Ivabradine in Managing Symptomatic Patients with Chronic Coronary Syndromes: A Clinically Oriented Approach
}

Luis Henrique W. Gowdak (D)

Received: September 2, 2021 / Published online: December 3, 2021

(c) The Author(s) 2021, corrected publication 2022

\begin{abstract}
Angina is a significant contributor to disability and impairment in quality of life in patients with chronic coronary syndromes (CCS). An elevated heart rate (HR) may trigger myocardial ischemia by increasing oxygen consumption and decreasing the diastolic time, compromising the coronary flow. HR-lowering strategies offer symptom control and prevent cardiovascular events in subgroups of patients with CCS. However, the best therapeutic approach to achieve the desired HR in patients with CCS can be challenging based on efficacy and tolerability. Guidelines usually propose $\beta$-blockers and/ or non-dihydropyridine calcium channel blockers (CCB) for angina patients with elevated HR. Nonetheless, there is no clear evidence of greater antianginal efficacy of this strategy versus an alternative HR-lowering agent. Ivabradine reduces the HR by blocking the $\mathrm{I}_{\mathrm{f}}$ current in the sinoatrial node without affecting myocardial contractility or vascular tone. The magnitude of the HR reduction by ivabradine is proportional to the initial HR, which decreases the risk of significant bradycardia. Ivabradine increases the diastolic time and the coronary flow reserve to a greater extent than $\beta$-blockers
\end{abstract}

L. H. W. Gowdak (ه)

Heart Institute (InCor-HCFMUSP), Av. Dr. Eneas de Carvalho Aguiar, 44, São Paulo, SP 05403-000, Brazil e-mail: luis.gowdak@incor.usp.br and favors collateralization, improving the regional blood flow. We present two clinical cases of patients with symptomatic CCS in whom HR control with ivabradine was fundamental for symptom control and improvement in left ventricular (LV) function. An earlier combination of ivabradine plus $\beta$-blockers would have provided more rapid symptom control and improved LV function in the first case. In the second case, the primary mechanism responsible for angina was most likely a coronary vasomotor abnormality, in which the use of $\beta$-blockers aggravated the discomfort. The combination of a dihydropyridine $\mathrm{CCB}$ plus ivabradine was highly influential in symptom control. Due to its effects beyond HR reduction and good tolerability, ivabradine should be considered an essential ally in managing patients with angina and high HR with or without LV dysfunction.

Keywords: Angina; Chronic coronary syndromes; Heart rate; Ivabradine; Symptomatic; Treatment 


\section{Key Summary Points}

Angina is a significant contributor to disability and impairment in quality of life in patients with chronic coronary syndromes (CCS).

Heart rate (HR) is one major determinant of myocardial oxygen consumption and, when elevated, may trigger myocardial ischemia and angina.

The best therapeutic approach to achieve the desired HR in patients with CCS based on efficacy and tolerability can be challenging.

Ivabradine is a unique agent, distinct from $\beta$-blockers and calcium channel blockers. It reduces HR without affecting myocardial contractility or vascular tone by acting on hyperpolarization-activated cyclic nucleotide-gated channels, a key player in the control of HR by the sinoatrial node.

We present two clinical cases in which a tailored approach towards more effective angina control was provided using ivabradine.

\section{DIGITAL FEATURES}

This article is published with digital features, including a talking head video, to facilitate understanding of the article. To view digital features for this article go to https://doi.org/10. 6084/m9.figshare.19583809.

\section{INTRODUCTION}

Angina is a significant contributor to disability and impairment in quality of life in patients with chronic coronary syndromes (CCS) [1], regardless of its precipitating mechanism [2]. 


\section{CLINICAL CASE \#1: A MIDDLE- AGED MAN WITH A LONG HISTORY OF CCS ON $\beta$-BLOCKERS AND WITH RECURRENT ANGINA}

Mr. S. is a 56-year-old man who suffered a myocardial infarction in 2003 that was treated by percutaneous coronary intervention (PCI). In 2007, he underwent bypass surgery for worsening angina and multivessel disease. He has a long history of type 2 diabetes mellitus, hypertension, hypercholesterolemia, and was previously a smoker. He was referred to our center in 2017 because of limiting, progressive angina in the previous 6 months.

When first seen, he was on aspirin $100 \mathrm{mg}$ once daily (od), atorvastatin $80 \mathrm{mg}$ od, bisoprolol $2.5 \mathrm{mg}$ od, olmesartan $20 \mathrm{mg}$ od, metformin $850 \mathrm{mg}$ twice daily (bid), and empagliflozin $25 \mathrm{mg}$ od. He used to play tennis but eventually had to stop because of the worsening angina, which bothered him considerably.

On examination, his HR was 72 beats per minute (bpm) and BP was 126/74 $\mathrm{mmHg}$. His physical examination was unremarkable. Electrocardiogram (ECG) showed sinus rhythm with $Q$ waves noted in inferior leads (Fig. 1); a transthoracic echocardiogram revealed moderate hypokinesis of the inferior wall and a global left ventricular ejection fraction (LVEF) of $40 \%$.

A diagnosis of recurrent angina on a previously asymptomatic patient with long-standing CCS was made. The dose of bisoprolol was increased to $5 \mathrm{mg}$ od. One month later, the patient complained of fatigue, dizziness, and lightheadedness upon standing, and angina had not improved. Bisoprolol was reduced to $2.5 \mathrm{mg}$ od, amlodipine $5 \mathrm{mg}$ od was added, and a myocardial perfusion scan was ordered (singlephoton emission computed tomography [SPECT]).

Six weeks later, symptoms had improved very modestly. HR was up to $80 \mathrm{bpm}$, and BP dropped to $114 / 64 \mathrm{mmHg}$. Figure 2 shows the results of the myocardial perfusion scan.

Medical therapy was considered a "failure," and coronary angiography (CA) was ordered (Fig. 3). The heart team assessed the angiography and judged the patient to be ineligible for another myocardial revascularization procedure: left internal mammary artery to the left anterior descending (LIMA-LAD) was patent, but the distal portion of the native vessel was severely diseased; there was also a chronic total occlusion of the right coronary artery (RCA). As the patient was still symptomatic, with

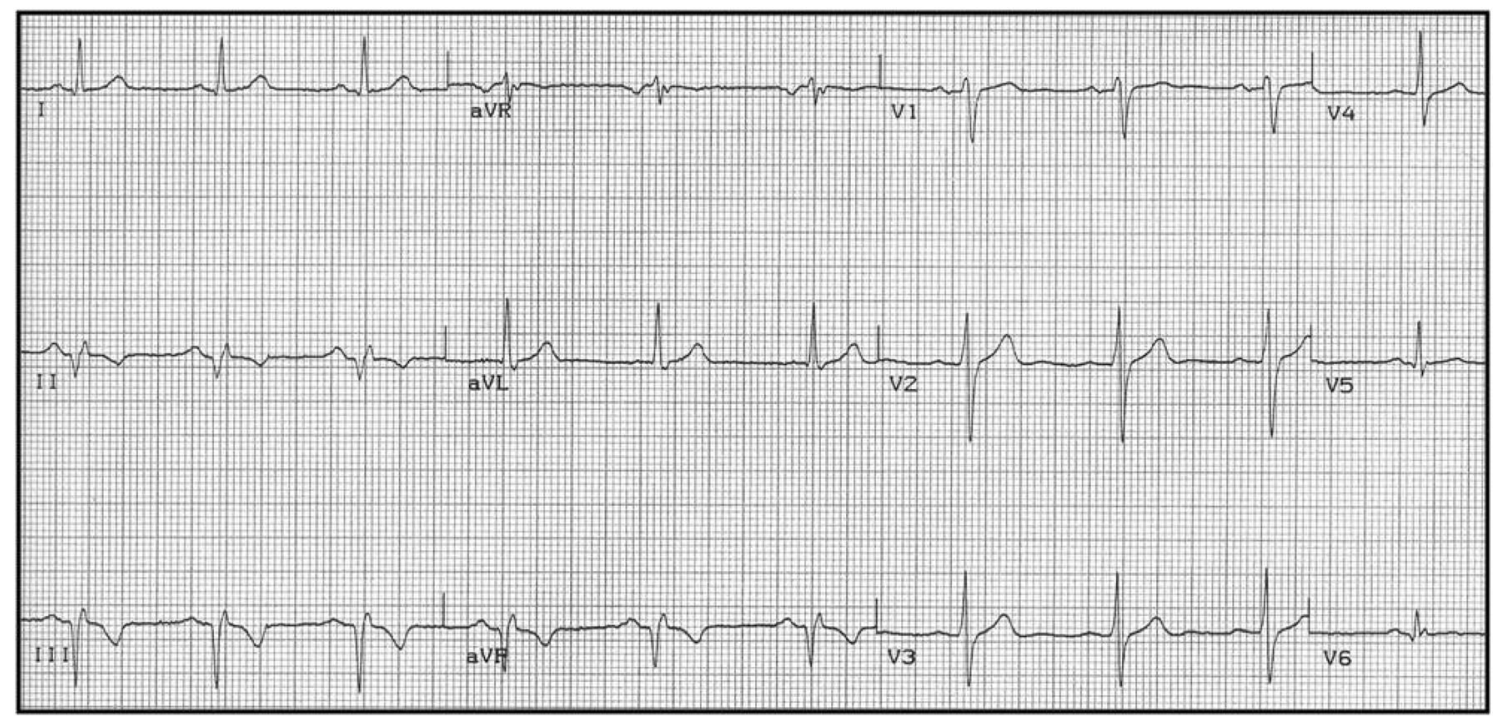

Fig. 1 Resting ECG showing a sinus rhythm (heart rate $\cong 75 \mathrm{bpm}$ ), Q waves in inferior leads (D2, D3, and aVF) with ST$\mathrm{T}$ abnormalities 


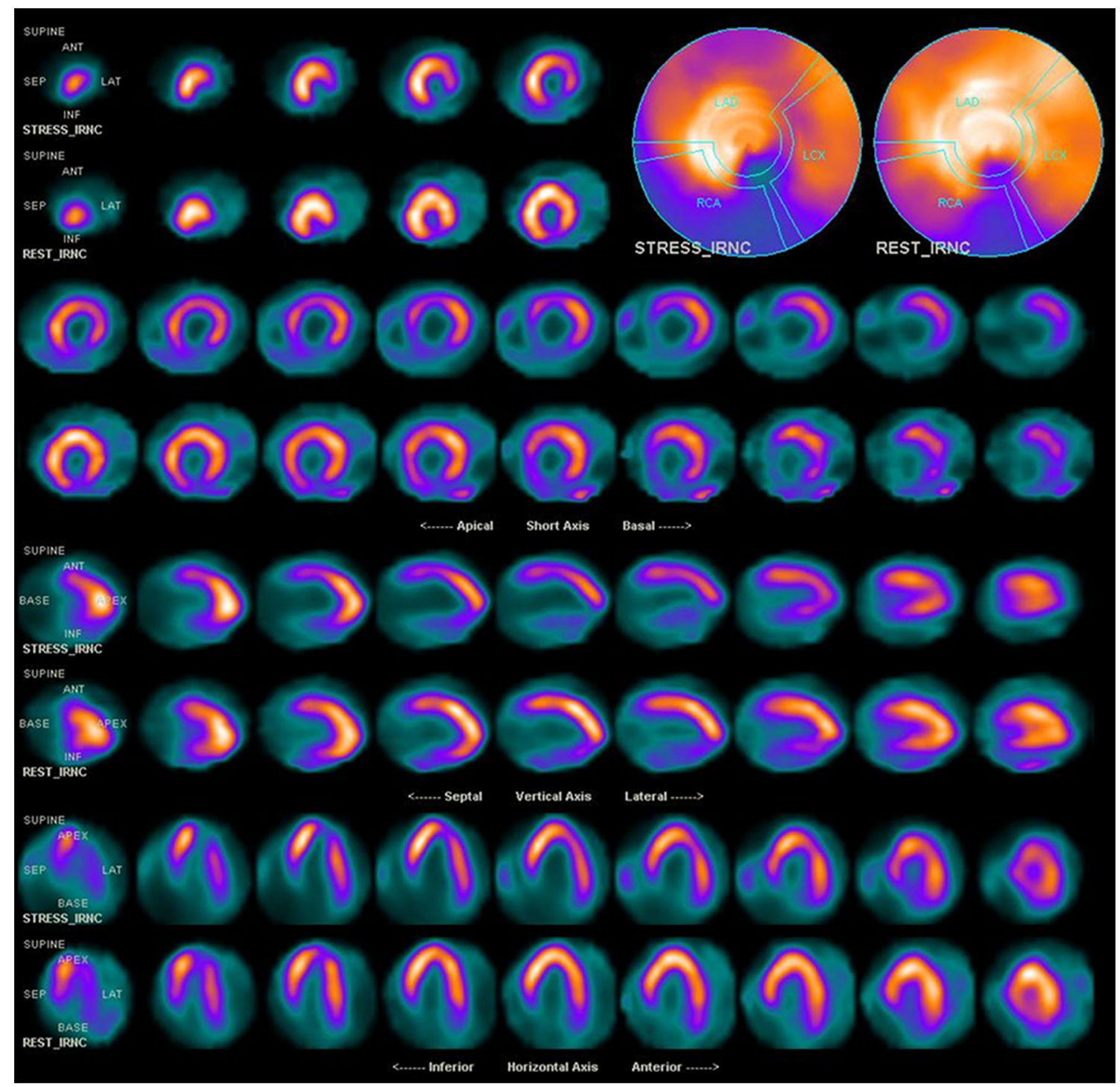

Fig. 2 Myocardial perfusion scan by SPECT (sestamibi) with dipyridamole performed in 2017 revealed moderateto-severe stress-induced myocardial perfusion abnormality in the anterior and lateral segments (reversible defect) and

borderline BP and sustained elevated HR on $\beta$ blockers, ivabradine $5 \mathrm{mg}$ bid was added.

One month later, the patient reported a significant clinical improvement, although he still experienced chest pain during more vigorous exercise. His HR was down to $68 \mathrm{bpm}$, and BP $118 / 72 \mathrm{mmHg}$. Ivabradine was up-titrated to $7.5 \mathrm{mg}$ bid. Three months later, the patient remained free of angina, having experienced a single episode during intercourse, which was inferior segments (fixed defect). The extension of myocardial ischemia was estimated to be $21 \%$ of the LV. The resting LVEF was 36\%

quickly relieved by resting. He was pleased with the treatment, with no side effects noted. HR was $60 \mathrm{bpm}$, and BP 120/74 $\mathrm{mmHg}$.

Three years later, the patient was still free of angina in his daily activities. Notably, he did not experience any cardiovascular events. Another myocardial perfusion assessment revealed a reduction in stress-induced myocardial ischemia from 21 to $6 \%$, with a corresponding increase in LVEF from 36 to $51 \%$ (Fig. 4). 

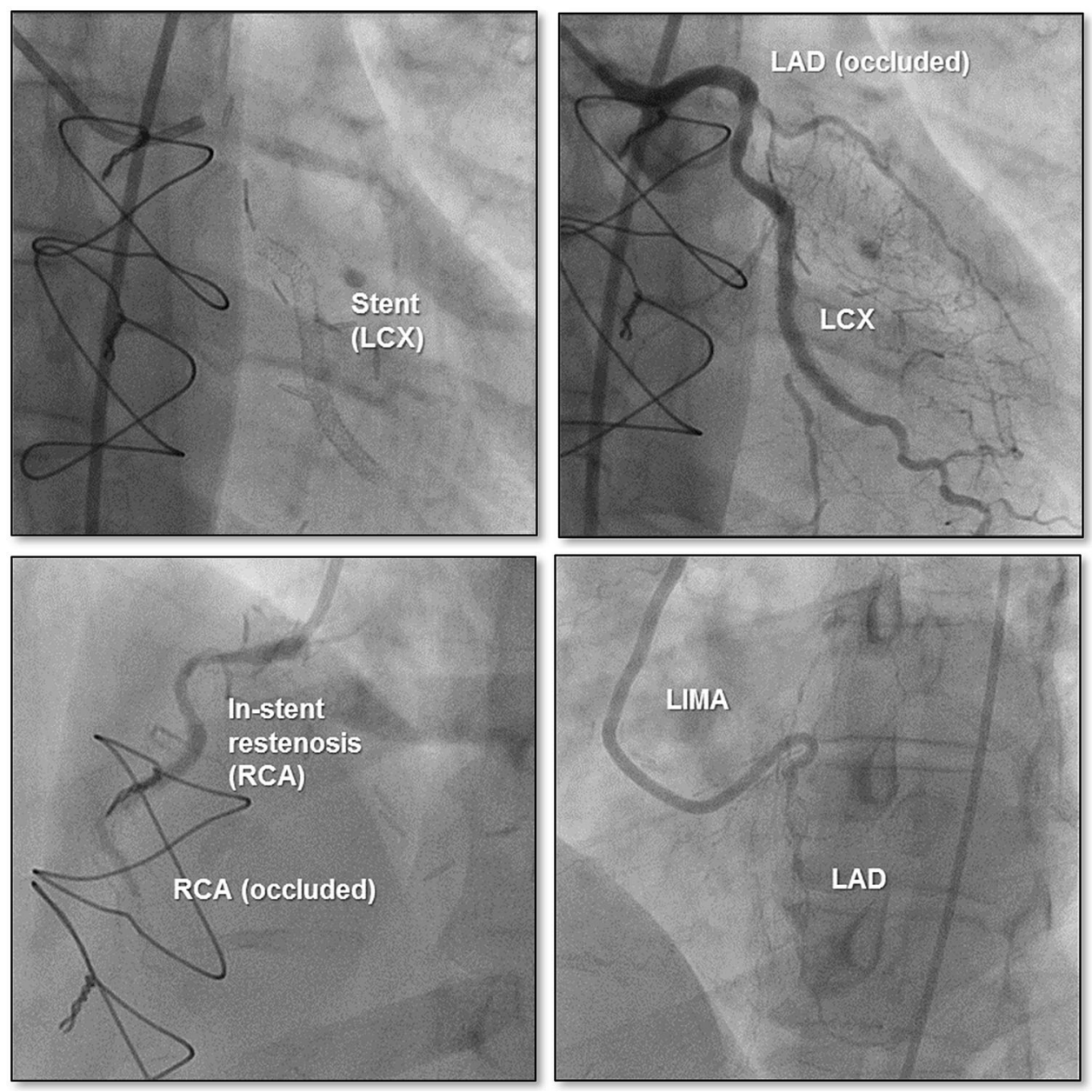

Fig. 3 Coronary angiography revealed a patent stent placed in the left circumflex coronary artery (LCX) and patent left internal mammary artery (LIMA) graft to the mid-LAD with a poor filling of the native LAD due to atherosclerosis progression in the native vessel (LAD) and the right coronary artery (RCA). There was a

\section{CLINICAL CASE \#2: A MIDDLE- AGED WOMAN WITH PREVIOUS PCIS COMPLAINING OF RECURRENT ANGINA UNRESPONSIVE TO $\beta$-BLOCKERS}

Mrs. P. is a 53-year-old woman referred to our hospital after a long history of CCS and multiple procedures. In 2010 she started complaining of oppressive chest pain, lasting more than $10 \mathrm{~min}$, sometimes evoked by exercise, but most often occurring at rest or with mental stress. She sought medical attention and was diagnosed with stable angina, hypertension, and mixed anxiety-depressive disorder. She had smoked 20 cigarettes/day since the age of 18 years. $\beta$ blockers and fluoxetine were prescribed without any improvement in her symptoms. She was sent for a CA, which showed no significant coronary stenoses.

Two years later, she was still having occasional chest pain, mainly evoked by mental stress. Although a stress myocardial perfusion scan showed normal distribution of the radioisotope and normal LVEF, a second CA was performed because of persistent symptoms (Fig. 5). Nonsignificant atherosclerosis of the RCA and the LAD was found. An antiplatelet 


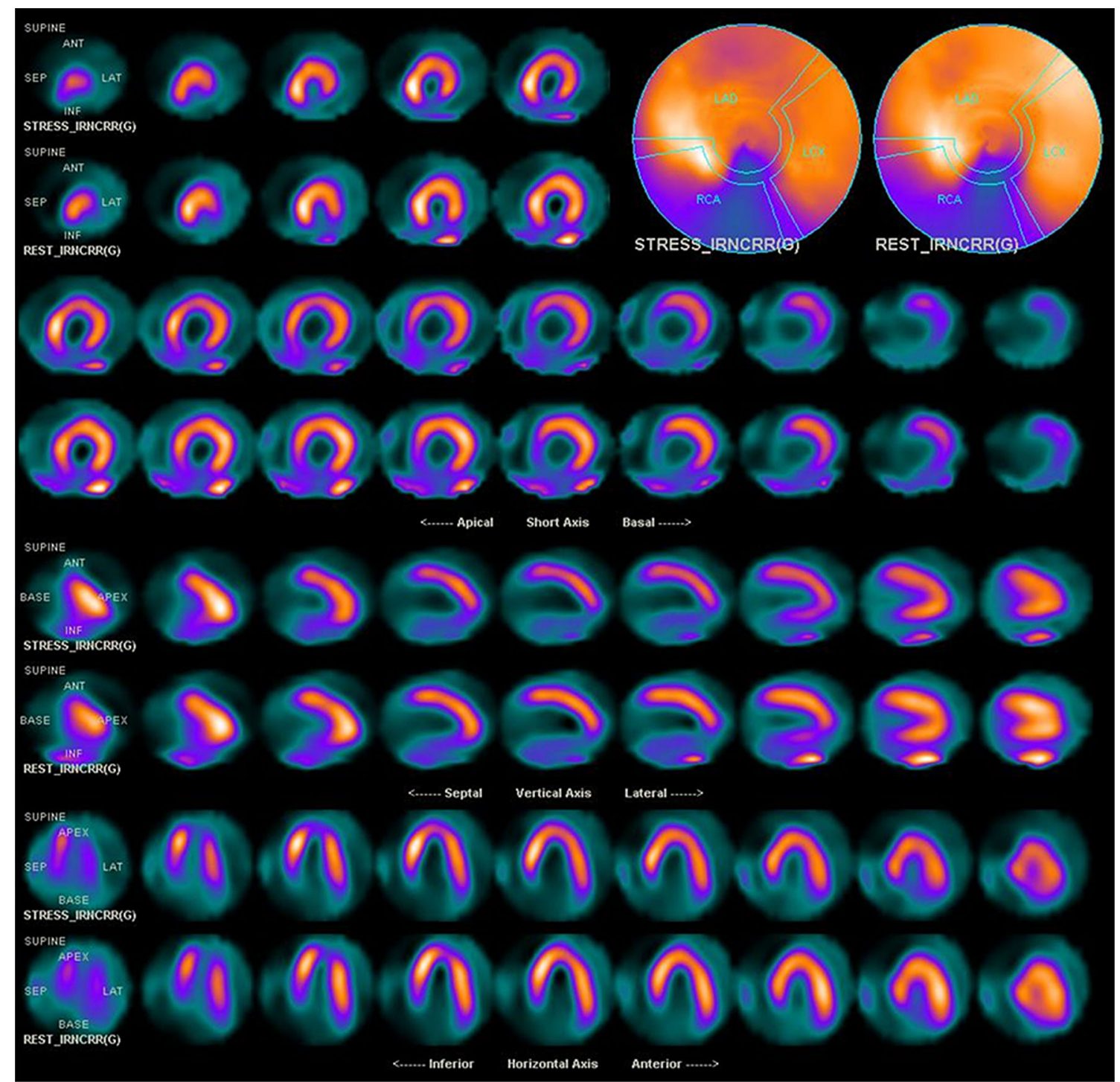

Fig. 4 Myocardial perfusion scan by SPECT (sestamibi) with dipyridamole performed in 2020 revealed mild stressinduced myocardial perfusion abnormality in the anterior and lateral segments (reversible defect) and inferior

agent and a high-intensity statin were prescribed, and the patient was strongly advised to quit smoking.

Between 2012 and 2017, she had several admissions to the emergency department (ED) for recurring chest pain. In 2017, she underwent a third CA for prolonged chest pain, and a drugeluting stent (DES) was placed in a proximal LAD lesion with $70 \%$ stenosis. segments (fixed defect). The extension of myocardial ischemia was reduced from 21 to $6 \%$ of the LV. The resting LVEF increased from 36 to $51 \%$

In March 2020, she again attended the ED for prolonged acute chest pain accompanied by nausea and profuse sweating. ECG was normal (Fig. 6), but high-sensitivity (hs)-troponin was elevated. The patient was treated for high-risk unstable angina and underwent a fourth CA (Fig. 7). PCI to the RCA with implantation of two DES was performed (Fig. 8). An echocardiogram revealed normal LV function with no structural abnormalities. She was kept on 

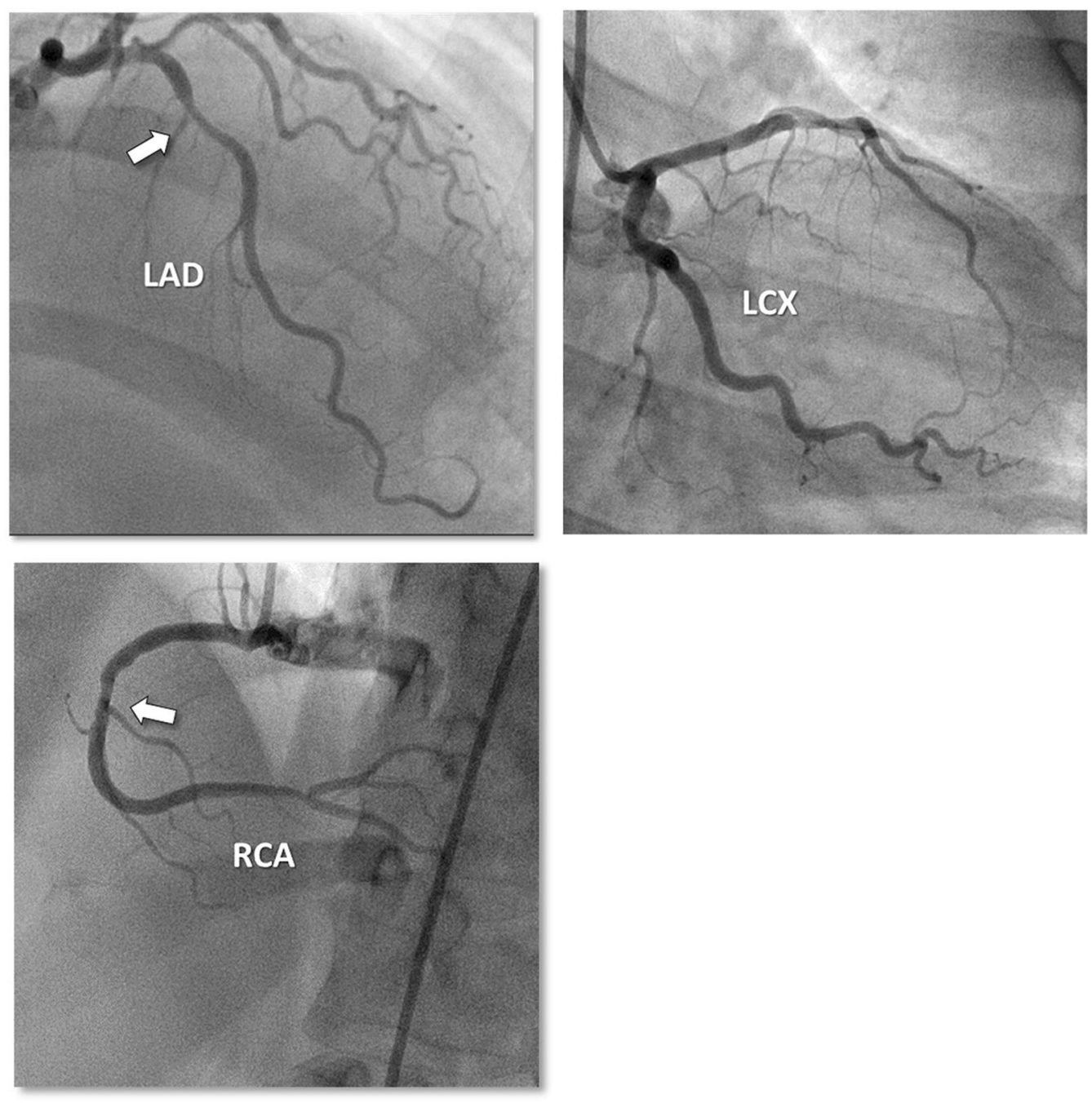

Fig. 5 Coronary angiography performed in 2012 showed non-obstructive lesions in the left anterior descending coronary artery (LAD) and right coronary artery (RCA) (arrows). LCX left circumflex coronary artery

atenolol $25 \mathrm{mg} / \mathrm{d}$, atorvastatin $80 \mathrm{mg} / \mathrm{d}$, enalapril $20 \mathrm{mg} / \mathrm{d}$, and dual antiplatelet therapy (aspirin $100 \mathrm{mg}+$ clopidogrel $75 \mathrm{mg} / \mathrm{d}$ ).

One month after the procedure, episodes of chest pain recurred at rest, predominantly late at night or early in the morning, with variable location (middle of the chest, neck, upper abdomen). Due to the COVID-19 pandemic, her scheduled appointment was canceled, but during a teleconsultation, she was asked to check her vitals with an automatic BP monitor: $\mathrm{HR}=82 \mathrm{bpm}$ and $\mathrm{BP}=118 / 66 \mathrm{mmHg}$. She was advised to increase the dosage of atenolol to $50 \mathrm{mg} / \mathrm{d}$. At her next teleconsultation, 1 month later, her chest pain was worse. Her new readings were: $\mathrm{HR}=74 \mathrm{bpm}$ and $\mathrm{BP}=106$ / $64 \mathrm{mmHg}$. She was once again instructed to increase the dose of atenolol to $100 \mathrm{mg} / \mathrm{d}$ and resume fluoxetine.

For the next 3 weeks, she felt rather well until she received a call from her daughter, who was being admitted for treatment of COVID-19. Afterward, she developed a sharp, severe pain in the middle of the chest associated with nausea, vomiting, and pallor, and she was brought to the ED. The ECG obtained during the episode of pain is shown in Fig. 9. The patient was medically treated for ST-elevation myocardial 


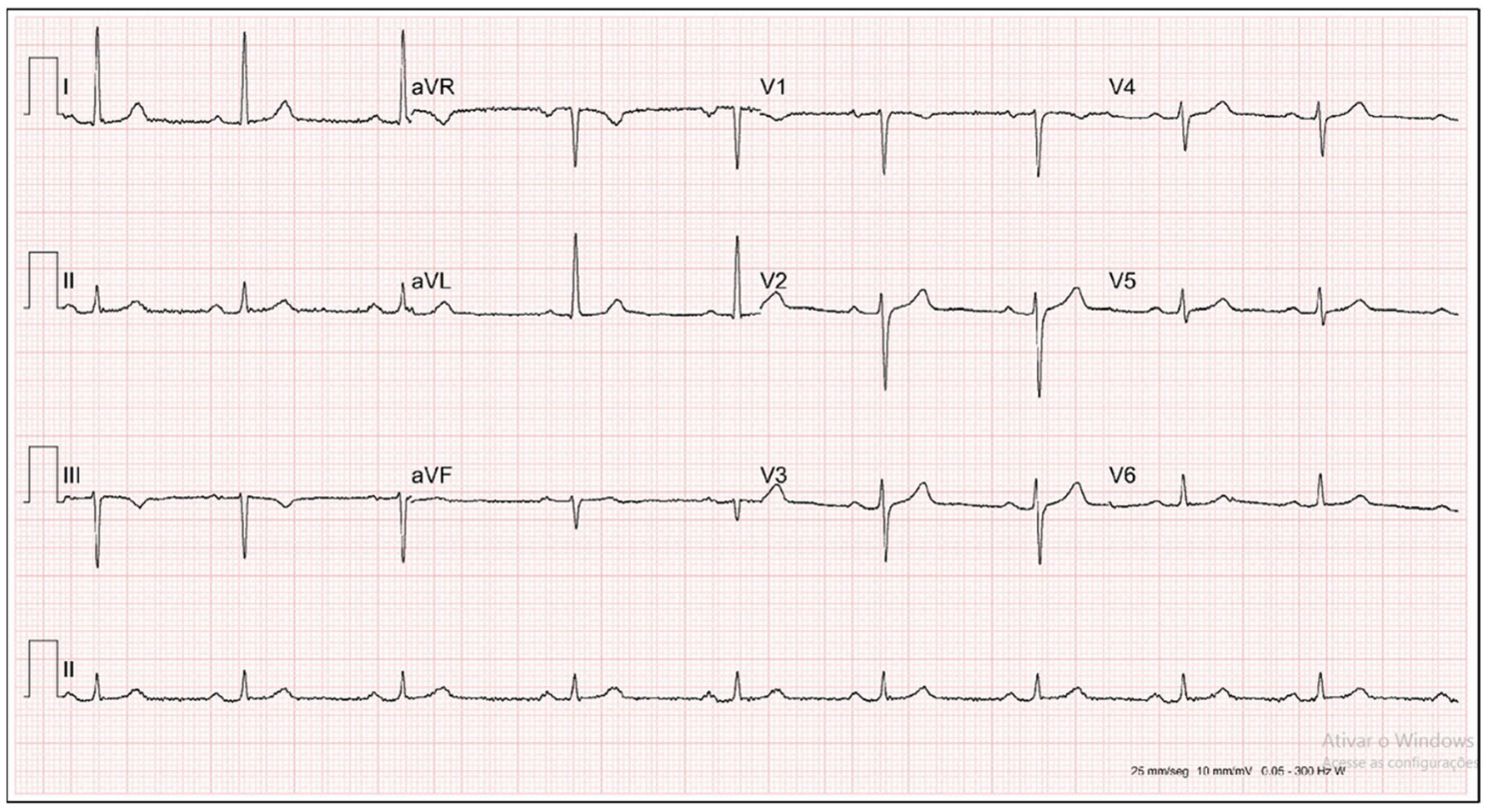

Fig. 6 Normal resting ECG was obtained after the resolution of the chest pain before reaching the emergency department

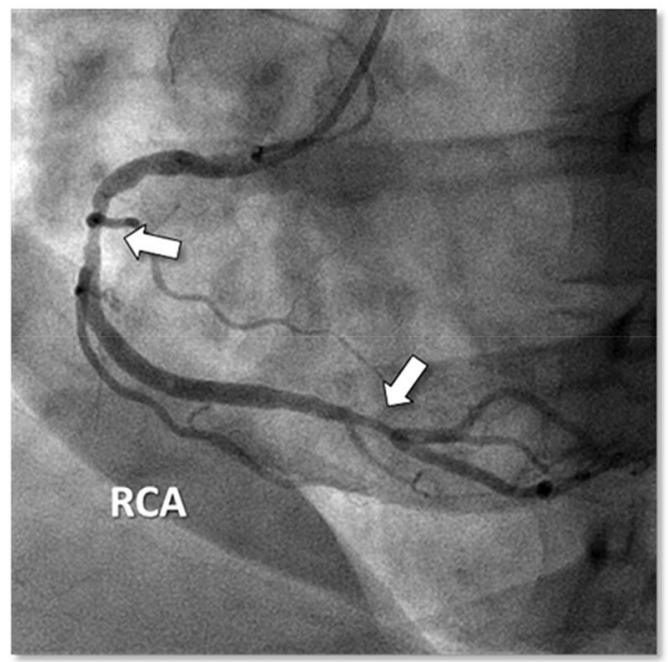

Fig. 7 Coronary angiography was performed in March 2020, showing mild progression of previously known atherosclerotic lesions in the right coronary artery (RCA)

infarction (STEMI) and immediately transferred to the catheterization laboratory. An extensive and severe narrowing of the RCA was found (Fig. 10, left), except where the two stents had been placed. Administration of nitrates relieved the spasm, and the RCA was found to be free of any significant disease (Fig. 10, right).

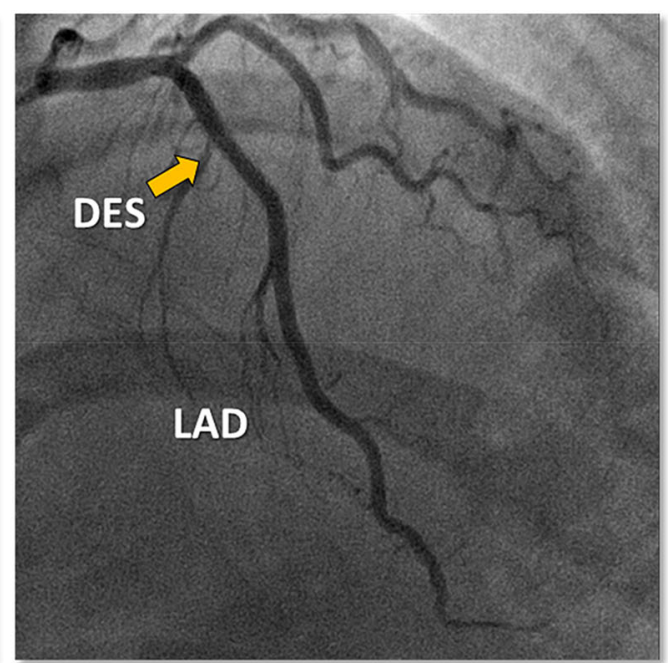

and a patent drug-eluting stent (DES) (arrow) in the proximal left anterior descending (LAD) coronary artery

The patient was admitted, atenolol was suspended, and she had an uneventful recovery. Before discharge, her vitals were: $\mathrm{HR}=72 \mathrm{bpm}$ and $\mathrm{BP}=138 / 82 \mathrm{mmHg}$. LV function was normal. Besides medical therapy for secondary prevention, she was given amlodipine $5 \mathrm{mg}$ od + ivabradine $5 \mathrm{mg}$ bid. Four weeks later, she 


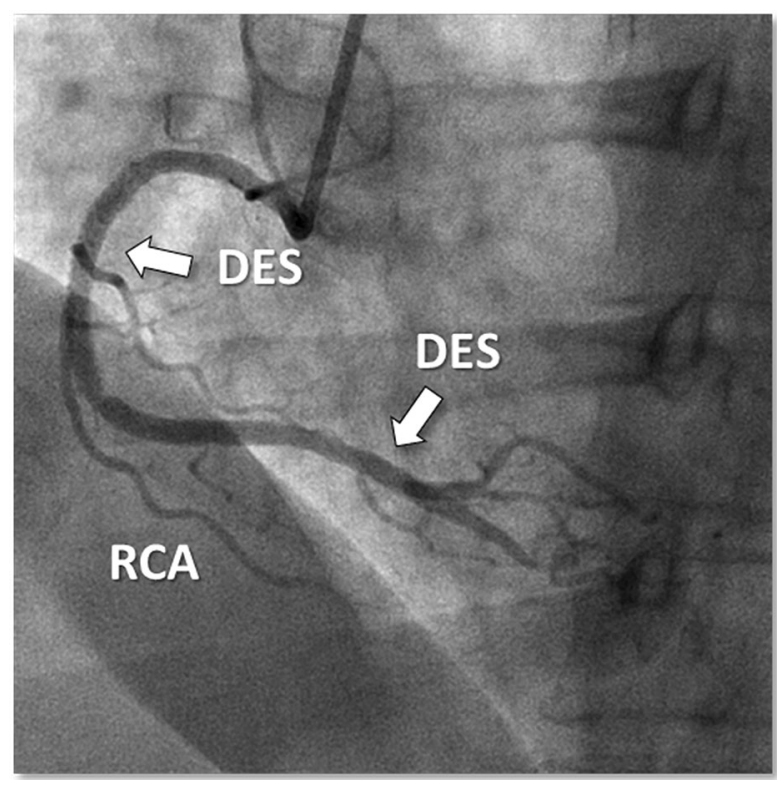

Fig. 8 The final result after two drug-eluting stents (DES) have been placed in the proximal and distal portion of the right coronary artery (RCA)

was feeling much better, with no recurrence of symptoms. HR was $60 \mathrm{bpm}$ and BP 124/76 mmHg. When last seen in March 2021, the patient had experienced no recurrence of angina; she had resumed her daily life without any discomfort, and her quality of life had greatly improved. She finally quit smoking and started walking $60 \mathrm{~min} /$ day. Physical examination revealed a $\mathrm{HR}$ of $58 \mathrm{bpm}$ and $\mathrm{BP}$ 118/72 mmHg.

\section{DISCUSSION}

Traditionally, $\beta$-blockers have been considered a key player in managing patients with angina and elevated HR, adjusted to limit it to 55 to $60 \mathrm{bpm}$. However, this strategy is frequently hampered by the low tolerability of increasing doses of $\beta$-blockers with nonsignificant additional benefits [9]. In clinical practice, the actual dosage of any $\beta$-blocker varies between 50 and $75 \%$ of the recommended maximal dosage for patients with stable angina or heart failure [10]. In a very extensive registry, including more than 33,000 patients with diagnosed stable coronary artery disease (CAD), nearly half of the patients treated with $\beta$-blockers had resting HR above $70 \mathrm{bpm}$. Amongst the symptomatic patients in the same registry, only

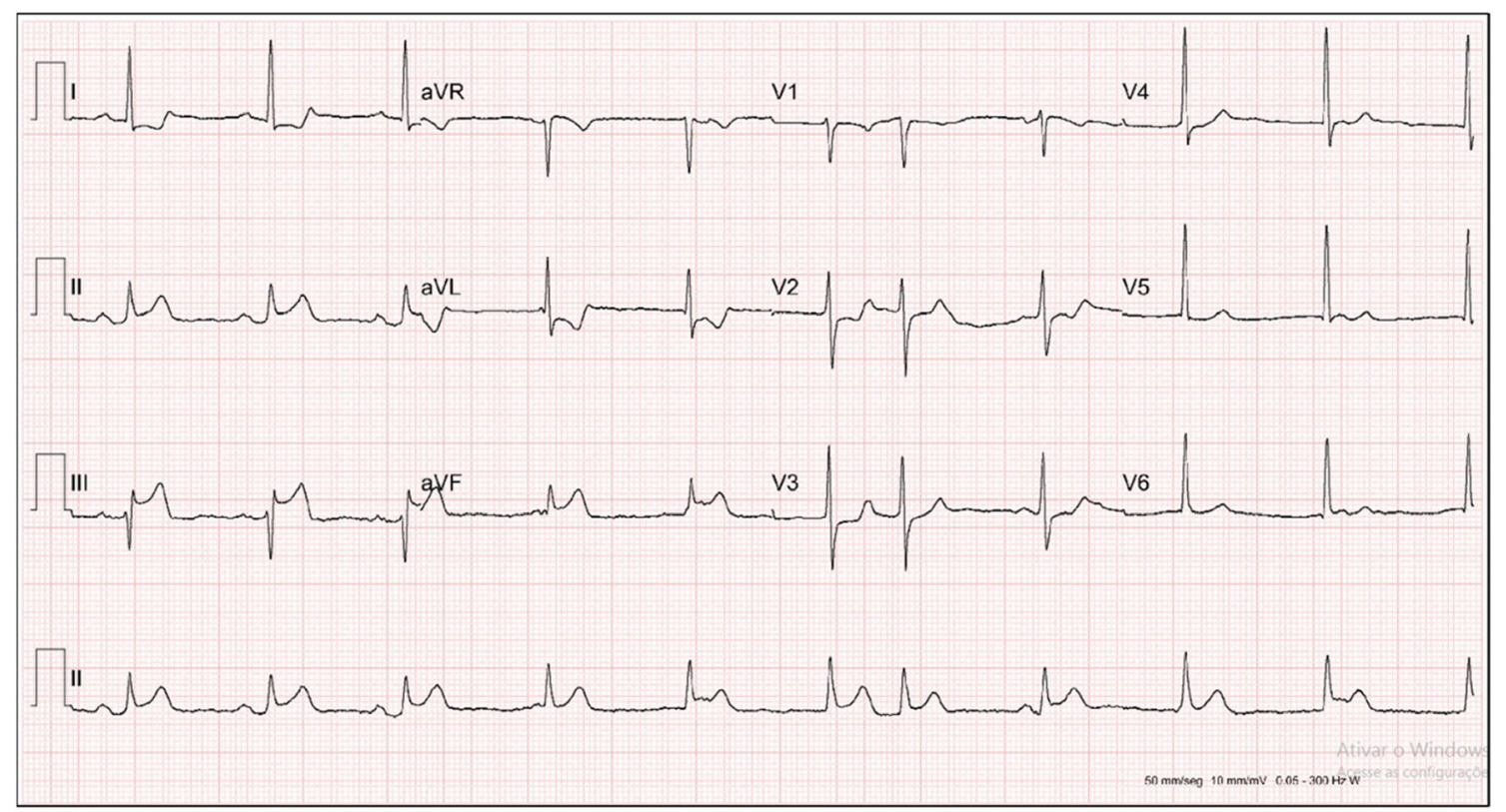

Fig. 9 Resting ECG obtained during an episode of acute chest pain showing ST-T segment elevation in inferior leads (D2, $\mathrm{D} 3$, and $\mathrm{aVF}$ ) and repolarization abnormalities in lateral leads (D1 and aVL) 

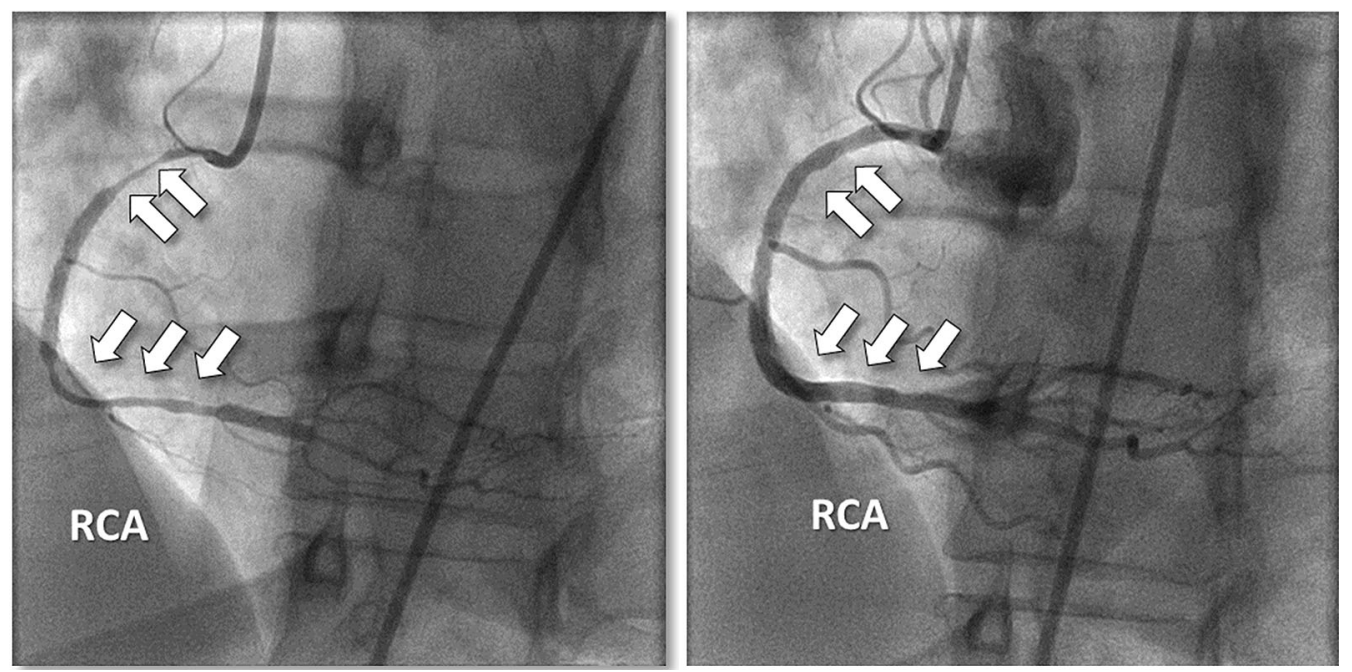

Fig. 10 Extensive narrowing of the right coronary artery (RCA) relieved by nitrates during STEMI

$22.1 \%$ achieved HR equal to or lower than $60 \mathrm{bpm}$ [11].

On the other hand, hypotension caused by increasing doses of $\beta$-blockers (or any BP-lowering antianginal agent) carries a high risk of worsening angina [12] and cardiovascular events [13]. The strategy of combining $\beta$-blockers with verapamil or diltiazem should be cautiously exercised due to the potential for developing worsening of heart failure, excessive bradycardia, or atrioventricular block.

In patients with angina and elevated $\mathrm{HR}$, the addition of ivabradine was more effective than the up-titration of $\beta$-blockers in reducing symptoms [14] and improving physical capacity [15]. The BEAUTIFUL trial showed that in patients with CCS and LVEF $<40 \%$ with a HR above $70 \mathrm{bpm}$, ivabradine on top of optimal medical therapy led to a $36 \%$ reduction in the risk of admission for fatal and nonfatal myocardial infarction and a 30\% reduction of coronary revascularization [16].

The clinical benefits and the safety profile of ivabradine may be explained by the unique mode of action of the drug. By precisely inhibiting the $\mathrm{I}_{\mathrm{f}}$ current on the sinus node, the magnitude of the HR reduction by ivabradine is proportional to the initial HR, which decreases the risk of significant bradycardia [17]. In the SHIFT trial, bradycardia leading to the permanent withdrawal from the study occurred in only $1 \%$ of patients on ivabradine [18].

Of particular interest in patients with angina, ivabradine increases the diastolic time, improves coronary blood flow both at rest [19] and during exercise [20], and improves the coronary flow reserve to a greater extent than $\beta$ blockers [21]. It also favors collateralization [22], improving the regional blood flow [23]. Finally, ivabradine may prevent deterioration of endothelial dysfunction and reduce the formation of reactive oxygen species and the atherosclerotic plaque area, as shown in experimental [24] and clinical studies [25]. All these processes elicited by ivabradine may contribute to the clinical benefits seen in patients with angina or myocardial ischemia.

We have presented two real clinical cases in patients with symptomatic CCS in whom HR control with ivabradine was fundamental for symptom control and improvement in LV function. The case studies are commonly observed in clinical practice yet pose a challenge for the attending physician to define the best medical therapy for symptom control. The patients differed in the primary mechanisms responsible for angina, but the addition of ivabradine to guideline-recommended first-line therapies for angina patients with elevated HR was well tolerated and provided both patients with rapid symptom relief. Ivabradine, due to 
its effects beyond HR reduction and good tolerability, should be considered as an early ally in managing patients with angina and an elevated HR with or without LV dysfunction, as proposed by the latest European Society of Cardiology (ESC) Guidelines [6].

\section{ACKNOWLEDGEMENTS}

The author thanks the participants of this study.

Funding. Servier funded the journal's rapid service fee for this article.

Medical Writing/Editorial Assistance. Editorial support was provided by Jenny Grice and funded by Servier.

Authorship. The named author meets the International Committee of Medical Journal Editors (ICMJE) criteria for authorship for this article, takes responsibility for the integrity of the work as a whole, and has given his approval for this version to be published.

Author Contribution. The author had full access to all of the data in this study and takes complete responsibility for the integrity of the data and accuracy of the data analysis.

Compliance with Ethics Guidelines. All procedures performed in studies involving human participants were in accordance with the ethical standards of the institutional and/or national research committee and with the 1964 Helsinki declaration and its later amendments or comparable ethical standards. Ethics committee approval was not required because patients' identities were kept confidential and no personal information was provided that could potentially break the doctor-patient confidentiality. Informed consent was obtained from all individual participants included in the study.

Disclosures. Luís Henrique W. Gowdak has received a speaker honorarium from Les Laboratoires Servier.
Data Availability. The datasets generated during and/or analyzed during the current study are available from the corresponding author on reasonable request.

Open Access. This article is licensed under a Creative Commons Attribution-NonCommercial 4.0 International License, which permits any non-commercial use, sharing, adaptation, distribution and reproduction in any medium or format, as long as you give appropriate credit to the original author(s) and the source, provide a link to the Creative Commons licence, and indicate if changes were made. The images or other third party material in this article are included in the article's Creative Commons licence, unless indicated otherwise in a credit line to the material. If material is not included in the article's Creative Commons licence and your intended use is not permitted by statutory regulation or exceeds the permitted use, you will need to obtain permission directly from the copyright holder. To view a copy of this licence, visit http://creativecommons.org/licenses/by$\mathrm{nc} / 4.0 /$.

\section{REFERENCES}

1. Geovanini GR, Gowdak LHW, Pereira AC, DanziSoares NJ, Dourado LOC, Poppi NT, et al. OSA and depression are common and independently associated with refractory angina in patients with coronary artery disease. Chest. 2014;146(1):73-80.

2. Ford TJ, Yii E, Sidik N, Good R, Rocchiccioli P, McEntegart $\mathrm{M}$, et al. Ischemia and no obstructive coronary artery disease: prevalence and correlates of coronary vasomotion disorders. Circ Cardiovasc Interv. 2019;12(12):e008126.

3. Kop WJ, Verdino RJ, Gottdiener JS, O'Leary ST, Bairey Merz CN, Krantz DS. Changes in heart rate and heart rate variability before ambulatory ischemic events(1). J Am Coll Cardiol. 2001;38(3): 742-9.

4. Levy BI, Heusch G, Camici PG. The many faces of myocardial ischaemia and angina. Cardiovasc Res. 2019;115(10):1460-70.

5. Diaz A, Bourassa MG, Guertin MC, Tardif JC. Longterm prognostic value of resting heart rate in 
patients with suspected or proven coronary artery disease. Eur Heart J. 2005;26(10):967-74.

6. Knuuti J, Wijns W, Saraste A, Capodanno D, Barbato E, Funck-Brentano C, et al. 2019 ESC Guidelines for the diagnosis and management of chronic coronary syndromes. Eur Heart J. 2020;41(3): 407-77.

7. Chen C, Kaur G, Mehta PK, Morrone D, Godoy LC, Bangalore $\mathrm{S}$, et al. Ivabradine in cardiovascular disease management revisited: a review. Cardiovasc Drugs Ther. 2021;35:1045-56.

8. Postea O, Biel M. Exploring HCN channels as novel drug targets. Nat Rev Drug Discov. 2011;10(12): 903-14.

9. Dimmitt SB, Stampfer HG, Warren JB. $\beta$-adrenoceptor blockers valuable but higher doses not necessary. Br J Clin Pharmacol. 2014;78(5):1076-9.

10. Tendera M, Fox K, Ferrari R, Ford I, Greenlaw N, Abergel $\mathrm{H}$, et al. Inadequate heart rate control despite widespread use of beta-blockers in outpatients with stable CAD: findings from the international prospective CLARIFY registry. Int J Cardiol. 2014;176(1):119-24.

11. Steg PG, Ferrari R, Ford I, Greenlaw N, Tardif JC, Tendera $\mathrm{M}$, et al. Heart rate and use of beta-blockers in stable outpatients with coronary artery disease. PLoS ONE. 2012;7(5):e36284.

12. Peri-Okonny PA, Patel KK, Jones PG, Breeding T, Gosch KL, Spertus JA, et al. Low diastolic blood pressure is associated with angina in patients with chronic coronary artery disease. J Am Coll Cardiol. 2018;72(11):1227-32.

13. Vidal-Petiot E, Ford I, Greenlaw N, Ferrari R, Fox $\mathrm{KM}$, Tardif JC, et al. Cardiovascular event rates and mortality according to achieved systolic and diastolic blood pressure in patients with stable coronary artery disease: an international cohort study. Lancet. 2016;388(10056):2142-52.

14. Glezer M, Vasyuk Y, Karpov Y. Efficacy of ivabradine in combination with beta-blockers versus uptitration of beta-blockers in patients with stable angina (CONTROL-2 Study). Adv Ther. 2018;35(3):341-52.

15. Amosova E, Andrejev E, Zaderey I, Rudenko U, Ceconi C, Ferrari R. Efficacy of ivabradine in combination with Beta-blocker versus uptitration of Beta-blocker in patients with stable angina. Cardiovasc Drugs Ther. 2011;25(6):531-7.
16. Fox K, Ford I, Steg PG, Tendera M, Ferrari R, Investigators B. Ivabradine for patients with stable coronary artery disease and left-ventricular systolic dysfunction (BEAUTIFUL): a randomised, double-blind, placebo-controlled trial. Lancet. 2008;372(9641):807-16.

17. Borer JS, Le Heuzey JY. Characterization of the heart rate-lowering action of ivabradine, a selective I(f) current inhibitor. Am J Ther. 2008;15(5): 461-73.

18. Swedberg K, Komajda M, Böhm M, Borer JS, Ford I, Dubost-Brama A, et al. Ivabradine and outcomes in chronic heart failure (SHIFT): a randomised placebo-controlled study. Lancet. 2010;376(9744): 875-85.

19. Dillinger JG, Maher V, Vitale C, Henry P, Logeart D, Manzo Silberman S, et al. Impact of ivabradine on central aortic blood pressure and myocardial perfusion in patients with stable coronary artery disease. Hypertension. 2015;66(6):1138-44.

20. Simon L, Ghaleh B, Puybasset L, Giudicelli JF, Berdeaux A. Coronary and hemodynamic effects of S 16257, a new bradycardic agent, in resting and exercising conscious dogs. J Pharmacol Exp Ther. 1995;275(2):659-66.

21. Tagliamonte E, Cirillo T, Rigo F, Astarita C, Coppola $\mathrm{A}$, Romano $\mathrm{C}$, et al. Ivabradine and bisoprolol on doppler-derived coronary flow velocity reserve in patients with stable coronary artery disease: beyond the heart rate. Adv Ther. 2015;32(8):757-67.

22. Gloekler S, Traupe T, Stoller M, Schild D, Steck H, Khattab A, et al. The effect of heart rate reduction by ivabradine on collateral function in patients with chronic stable coronary artery disease. Heart. 2014;100(2):160-6.

23. Camici PG, Gloekler S, Levy BI, Skalidis E, Tagliamonte $\mathrm{E}$, Vardas $\mathrm{P}$, et al. Ivabradine in chronic stable angina: effects by and beyond heart rate reduction. Int J Cardiol. 2016;215:1-6.

24. Custodis F, Baumhäkel M, Schlimmer N, List F, Gensch C, Böhm M, et al. Heart rate reduction by ivabradine reduces oxidative stress, improves endothelial function, and prevents atherosclerosis in apolipoprotein E-deficient mice. Circulation. 2008;117(18):2377-87.

25. Jedlickova L, Merkovska L, Jackova L, Janicko M, Fedacko J, Novakova B, et al. Effect of ivabradine on endothelial function in patients with stable angina pectoris: assessment with the Endo-PAT 2000 device. Adv Ther. 2015;32(10):962-70. 